\title{
Effects of hedgerow enhancement as a net zero strategy on
}

\section{farmland biodiversity: a rapid review [version 1; peer review: 2}

\section{approved]}

\author{
Megan E. Tresise (iD), Mark S. Reed (iD), Pippa J. Chapman (iD)3 \\ ${ }^{1}$ School of Biology, University of Leeds, Leeds, West Yorkshire, LS29JT, United Kingdom \\ ${ }^{2}$ Thriving Natural Capital Challenge Centre - Department of Rural Economies, Environment \& Society, Scotland's Rural College \\ (SRUC), Edinburgh, EH93JG, United Kingdom \\ ${ }^{3}$ School of Geography, University of Leeds, Leeds, West Yorkshire, LS29JT, United Kingdom
}

V1 First published: 24 Sep 2021, 3:23

https://doi.org/10.35241/emeraldopenres.14307.1

Latest published: 24 Sep 2021, 3:23

https://doi.org/10.35241/emeraldopenres.14307.1

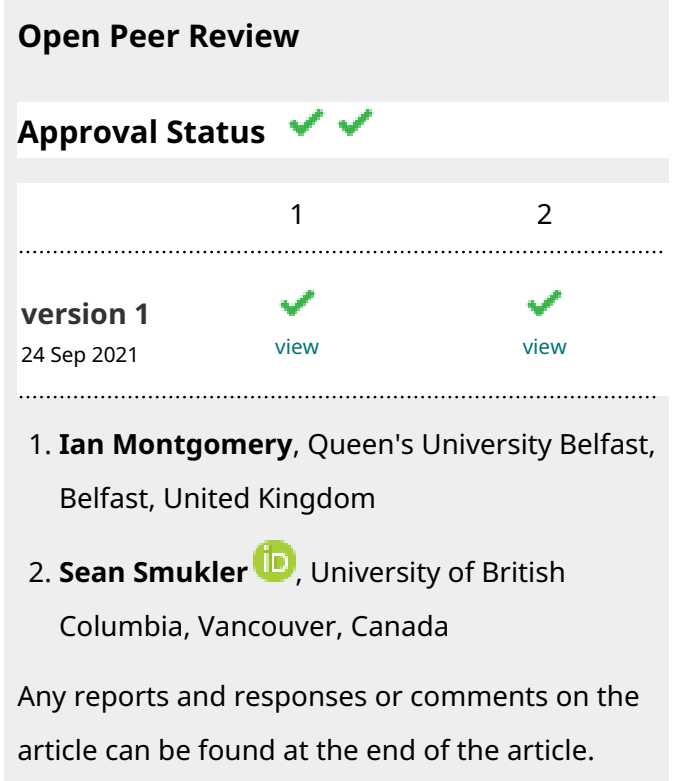

\begin{abstract}
In order to mitigate the effects of climate change, the UK government has set a target of achieving net zero greenhouse gas (GHG) emissions by 2050. Agricultural GHG emissions in 2017 were 45.6 million tonnes of carbon dioxide equivalent $\left(\mathrm{CO}_{2} \mathrm{e} ; 10 \%\right.$ of UK total GHG emissions). Farmland hedgerows are a carbon sink, storing carbon in the vegetation and soils beneath them, and thus increasing hedgerow length by $40 \%$ has been proposed in the UK to help meet net zero targets. However, the full impact of this expansion on farm biodiversity is yet to be evaluated in a net zero context. This paper critically synthesises the literature on the biodiversity implications of hedgerow planting and management on arable farms in the UK as a rapid review with policy recommendations. Eight peer-reviewed articles were reviewed, with the overall scientific evidence suggesting a positive influence of hedgerow management on farmland biodiversity, particularly coppicing and hedgelaying, although other boundary features, e.g. field margins and green lanes, may be additive to net zero hedgerow policy as they often supported higher abundances and richness of species. Only one paper found hedgerow age effects on biodiversity, with no significant effects found. Key policy implications are that further research is required, particularly on the effect of hedgerow age on biodiversity, as well as mammalian and avian responses to hedgerow planting and management, in order to fully evaluate hedgerow expansion impacts on biodiversity.
\end{abstract}

\section{Keywords}

Rapid review, hedgerows, net zero, farmland biodiversity, climate change mitigation 
This article is included in the N8 AgriFood

N8 AgriFood

collection.

Corresponding author: Megan E. Tresise (bs15m2t@leeds.ac.uk)

Author roles: Tresise ME: Conceptualization, Data Curation, Formal Analysis, Investigation, Methodology, Project Administration, Writing - Original Draft Preparation, Writing - Review \& Editing; Reed MS: Funding Acquisition, Resources, Supervision, Writing - Review \& Editing; Chapman PJ: Writing - Review \& Editing

Competing interests: No competing interests were disclosed.

Grant information: This work was funded by Research England QR-SPF funds from the University of Leeds and University of York. The funders had no role in study design, data collection and analysis, decision to publish, or preparation of the manuscript.

Copyright: (c) 2021 Tresise ME et al. This is an open access article distributed under the terms of the Creative Commons Attribution License, which permits unrestricted use, distribution, and reproduction in any medium, provided the original work is properly cited.

How to cite this article: Tresise ME, Reed MS and Chapman PJ. Effects of hedgerow enhancement as a net zero strategy on farmland biodiversity: a rapid review [version 1; peer review: $\mathbf{2}$ approved] Emerald Open Research 2021 , 3:23

https://doi.org/10.35241/emeraldopenres.14307.1

First published: 24 Sep 2021, 3:23 https://doi.org/10.35241/emeraldopenres.14307.1 


\section{Introduction}

The UK government has agreed to achieve a target of net zero greenhouse gas (GHG) emissions by 2050, contributing to the Paris Agreement goal of keeping global surface temperatures well below $2^{\circ} \mathrm{C}$ (Roe et al., 2019). The term 'net zero' is fairly recent, although much of the research literature and policy are already familiar with other terms including 'net negative' (Smith, 2016) and 'carbon neutral'. All carry similar meaning involving GHG sinks equalling or exceeding GHG emission sources to mitigate further climate change. However, owing to the severity of predicted future climate impacts due to a $1.5^{\circ} \mathrm{C}$ and $2^{\circ} \mathrm{C}$ world (Roe et al., 2019), net zero has been introduced in the UK with the goal of mitigating and offsetting emissions to reach a net footprint of zero emissions. The UK has already demonstrated a reduction in overall GHG emissions, with estimates from 2019 showing a $43.8 \%$ decline in overall emissions since 1990, at 454.8 million tonnes of carbon dioxide equivalent $\left(\mathrm{MtCO}_{2} \mathrm{e}\right)$, and a decrease of $2.8 \%$ from 2018. These declines are largely the result of reduced fossil fuel usage and increased reliance on renewable energy sources, e.g. wind and solar power, through technological and scientific advancements.

Recent Department for Business, Energy and Industrial Strategy [BEIS] and Scottish Government reports on the 2019 agricultural emissions statistics found that farming emissions in England and Scotland had fallen $13 \%$ and $12.7 \%$, respectively, since 1990. This was largely the result of reduced livestock numbers, partly from disease outbreaks and changes to dairy milk quotas, and better nutrient management through reduced reliance on inorganic fertilisers owing to improved nutrient use efficiency and nutrient management plans. However, $70 \%$ of the UK land area is used for agriculture and is responsible for $10 \%$ of the UK's GHG emissions, with dominant gases being methane $\left(\mathrm{CH}_{4}\right)$ and nitrous oxide $\left(\mathrm{N}_{2} \mathrm{O}\right)$, contributing roughly $54 \%$ and $32 \%$ of agricultural emissions, respectively. Unlike many other economic sectors, the farming sector provides a unique opportunity for removing carbon (C) directly from the atmosphere during photosynthesis in farm crops and perennial plants, storing the $\mathrm{C}$ in aboveand below-ground biomass and soils (Amelung et al., 2020; Paustian et al., 2016; Smith, 2012). The National Farmers Union (NFU) Farming's 2040 Goal report suggests that one path to net zero agriculture will rely heavily on the sequestration of $\mathrm{C}$ in farmland soils and vegetation, through strategies such as cover cropping, agroforestry and the expansion of semi-natural features, e.g. hedgerows.

Hedgerows are a common feature of the UK landscape, with over $500,000 \mathrm{~km}$ of hedgerows across the entire UK (Carey et al., 2007), and were primarily established for stock fencing and separation of fields (Graham et al., 2018). During the latter half of the twentieth century, intensification of agriculture increased to meet food demand, which included the removal of field boundaries to make space for larger production areas. It was estimated that around $127,000 \mathrm{~km}$ of hedgerows were lost between 1984 and 1990, largely as a result of policy at this time (Petit et al., 2003). Today, however, hedgerows are an increasingly important part of the landscape, with farmers being given the opportunity to plant and manage their hedgerows in return for remuneration (Staley et al., 2012). These options are Agri-Environment Schemes (AES), and they form part of the UK's Countryside Stewardship Mid- and Higher-Tier agreements (e.g. BN7 Hedgerow gapping-up, BN11 Planting new hedges). Hedges require regular management to prevent overgrowth into lines of trees. Although too frequent trimming can also reduce the flowering of hedgerow plant species, e.g. Crataegus monogyna (Hawthorn) and cause gaps in the hedge line (Graham et al., 2018). Hedgelink's leaflet The Hedgerow Management Cycle \& Scale suggests that trimming is often performed using a mechanical flail on a tractor arm, although other methods include the use of a circular saw or manual cutting. This type of management is usually performed every one, two or three years to maintain hedge height and width, whilst promoting flowering and berry production. On longer timescales, hedgerows require a more drastic type of management to promote new shoots and branch growth, particularly if they have been neglected or over-managed and have become a line of trees or gappy. Long-term (every 10+ years) management includes laying, coppicing and gapping-up. Hedgelaying is a common practice whereby hedge stems are partly cut through and laid over with some weaving of cut stems to produce a dense rejuvenated hedge. On the other hand, coppicing involves hedge stems being completely cut through and removed at ground level allowing regrowth of the stools (hedge stem bases). Gapping-up is essentially the planting of new hedgerow plants in the gaps of rejuvenated hedges to ensure a denser mature hedge.

Farmland, despite being heavily anthropogenically modified, is an important habitat for a wide range of taxa, providing food resources and shelter in fields and in the semi-natural habitats at field edges. Hedgerows in particular are considered wildlife corridors, facilitating a more heterogeneous landscape and dispersal network between less disturbed patches of land and also providing refugia for many migratory species, thus their extensive removal during agricultural intensification likely had severe consequences for biodiversity loss in the farmed landscape (Burel, 1996; Donald et al., 2001). When these linear features are planted and managed regularly, they become vital habitats for many invertebrates, birds, mammals and plants. For example, yellowhammers (Emberiza citrinella) are a red-listed species that breed predominantly in farmland hedgerows and their populations have been shown to depend largely on specific hedgerow characteristics (Green et al., 1994) and adjacent crop rotation (Tresise et al., 2021). Furthermore, many Lepidopteran species utilise hedgerows for larval food resources and winter refugia (Staley et al., 2016), but have also been shown to restrict movement of butterflies (Dover \& Fry, 2001).

Both the NFU and Committee on Climate Change (CCC) have released reports outlining key strategies for net zero GHG emissions for agriculture and more general land-based sectors, respectively. The CCC recommend a $40 \%$ extension of 
hedgerows in the UK, equating to roughly 200,000 $\mathrm{km}$ of newly planted hedges, which they advise will provide biodiversity benefits through new habitat creation. Similar hedgerow expansion recommendations come from the NFU for England and Wales, although no target expansion or length is given, with claims of $0.5 \mathrm{MtCO}_{2} \mathrm{e}$ GHG savings per year in hedgerows alone. The later CCC report suggests areas of agroforestry (trees planted within cropland and grasslands) should increase to $10 \%$, and hedgerow area should reach 181,000 ha by 2050, delivering total savings of $6 \mathrm{MtCO}_{2} \mathrm{e}$ by 2050. Recent research suggests that cropland established hedgerows increase soil organic carbon (SOC) stocks by $32 \%( \pm 23 \%)$ and estimate that total carbon sequestration (in soil and biomass) of cropland, temperate hedgerows to be 5.2 mega gram $(\mathrm{Mg}) \mathrm{C} \mathrm{ha}^{-1}$ and $2.1 \mathrm{Mg} \mathrm{C}^{-1}$ for a period of 20 years and 50 years, respectively (Drexler et al., 2021; see also Axe et al., 2017).

The CCC's 2020 report acknowledges hedgerows for their benefits towards carbon removal and storage to mitigate climate change, for livestock (e.g. shelter), for minimising water pollution, as well as improving soil health and biodiversity. However, the report also demonstrates that the creation of hedgerows may not be as cost-effective as other strategies outlined for net zero, such as afforestation, mainly due to implementation and management costs. Costs arise from the initial planting of new hedges and subsequent maintenance. Furthermore, biodiversity values were not considered in the cost-benefit analyses, despite hedgerows being a key habitat for many farmland taxa.

Little is known about the effects of net zero strategies on biodiversity, which could be considerable, as many farmland-based initiatives involve physical changes in the landscape that may alter the farm ecology. Specifically, there are currently no systematic reviews that evaluate the implications of hedgerow planting or enhancement for climate mitigation on farmland biodiversity. Although there are reviews discussing the role of hedgerow structure and characteristics for farmland biodiversity with the rationale of improving hedgerow management policy (e.g. Graham et al., 2018), these reviews do not consider the effects of new hedgerow establishment and enhancement on biodiversity. If hedgerow expansion and enhancement is to be promoted as one of the options to mitigate climate change, then it is important to understand the potential implications of hedgerow planting and subsequent management on the biodiversity that inhabit or forage in and around hedgerows as they mature over time.

This review therefore provides a systematic collation and narrative synthesis of primary research to answer the following questions:

1. What are the effects of hedgerow planting and enhancement on biodiversity in arable farming systems of the UK?

2. Are there any contingencies of enhancing hedgerows as an effective net zero strategy in a biodiversity context?

The findings are of relevance to policy decisions on hedgerow planting as a GHG mitigation strategy as part of the UK net zero strategy, and can be used to identify contingencies or alternative strategies that could minimise risks to biodiversity whilst maintaining or improving progress towards net zero targets.

\section{Methods}

Search strategy

Research relating to the main objectives was searched for in two main scientific databases and one broader database to capture any relevant grey literature:

- ISI Web of Science - by topic

- Scopus - by title/abstract/keywords

- Google Scholar - by relevance; first 100 hits

The main search strings used were the same for Web of Science and Scopus, which allowed for wildcard operators, whereas Google Scholar only accepted simple Boolean operators (AND, OR, NOT) and limited search terms, thus multiple versions of only key words were used in the string to capture the relevant studies (Table 1).

Additionally, once the literature search had been narrowed down to only the studies for full text review, the bibliographies

Table 1. Search strings used in the databases to find relevant literature.

\section{Database Search strings}

Web of Science/Scopus (farm* OR arable OR agri* OR crop* OR “hedgerow species") AND (hedge* OR "planting" OR enhance* OR manage* OR "increase* hedge*") AND (prun* OR coppice* OR lay* OR "decrease* hedge*" OR boundar* OR "semi natural habitat*") AND (biodiversity OR richness OR abundance) AND "UK"

Google Scholar

(farm OR arable OR agriculture) AND (hedge OR "planting" OR enhance OR manage OR "increase hedge") AND (pruning OR coppice OR lay OR "decrease hedge" OR boundary OR boundaries OR "semi natural habitat") AND (biodiversity OR richness OR abundance) AND "UK" 
of the final reviewed papers were searched for any relevant research that had not been picked up by the keyword search. The searching stage of this rapid review was undertaken in March 2020.

\section{Inclusion and exclusion criteria}

Inclusion criteria. The main inclusion criteria followed the standard 'Population, Intervention, Comparison, Outcome and Study design' (PICOS) format (Higgins et al., 2020) found in most systematic reviews (Table 2). An initial scope of the literature found little to no primary research focussing on hedgerow planting in an experimental, observational or time-series design, so final search terms included interventions focussed more on management aspects that would be considered as enhancement of hedgerows. Additionally, arable farming studies were the focus population, as compared to grassland systems, due to the extensive list of papers found during the initial scoping using more general farming terms. Furthermore, livestock farming systems on grassland often benefit from moveable fences that allow rotational grazing of the land, whereas hedgerow expansion policy will require more permanent carbon sink assets to contribute to net zero. Therefore, it was deemed more appropriate to only analyse arable (cropland) farming systems.

Exclusion criteria. Owing to the time limitations of rapid reviews, several exclusions to the systematic review of papers were employed. The following criteria were used to exclude studies in all three database searches:

- Only English language

- Only primary research - i.e. reviews, comments, letters, book chapters etc. were excluded
- Model simulation studies were excluded - i.e. where outcomes have not been measured experimentally or in an observational context; studies where data was collected and then modelled statistically to determine relationships and associations were included

Sifting. The first sift of papers filtered through only titles and abstracts. Any obviously irrelevant studies were excluded from further sifts and any studies where the title and abstract were ambiguous, and so relevance was uncertain, were included for full text review. This was often the case when papers referred to hedgerows as semi-natural boundaries, field margin habitats and linear features. Although these terms are technically correct in describing hedgerows, they could also describe other farmland features that would be irrelevant to this review unless compared with hedgerows.

The second sift was a full text review of the finalists from the first sift from all three databases, minus duplicates. Full PDF copies were obtained and read in full, then inclusion and exclusion criteria were applied. Any research irrelevant to the main question was removed from further review and data extraction. Finally, the bibliographies of finalist papers were also searched for relevant literature meeting the inclusion and exclusion criteria.

\section{Quality appraisal}

Owing to the limited time allowed for rapid review, a simplified quality appraisal process was applied to the studies analysed (Thomas et al., 2013; Tricco et al., 2015). It was deemed appropriate to consider whether authors had identified causation from the interventions studied, influenced by

Table 2. PICOS information used to identify and narrow down relevant literature.

\begin{tabular}{|l|l|}
\hline PICos & Inclusion criteria \\
\hline Population & $\begin{array}{l}\text { Arable farms in the UK; majority arable if mixed } \\
\text { Farmland biodiversity }\end{array}$ \\
\hline Intervention & $\begin{array}{l}\text { Planting of hedgerows } \\
\text { Enhancement of hedgerows through planting or changes in management, e.g. short term trimming frequency, } \\
\text { long term rejuvenation technique etc. } \\
\text { Will also consider papers looking into the benefits of particular hedgerow characteristics to farmland } \\
\text { biodiversity if study design is experimental or controlled in some way }\end{array}$ \\
\hline Comparison & $\begin{array}{l}\text { Time-lag from hedgerow management (i.e. years since last management) or planting (e.g. new vs. old) } \\
\text { Less traditional management techniques, e.g. conservation-focussed techniques, intensities of management } \\
\text { Comparisons of hedgerow with other arable boundary features in terms of biodiversity outcomes (below) }\end{array}$ \\
\hline Outcome & $\begin{array}{l}\text { Biodiversity richness } \\
\text { Abundance }\end{array}$ \\
\hline Study design & $\begin{array}{l}\text { Boundary-level, field-scale or landscape-scale studies } \\
\text { Experimental, observational and time-series }\end{array}$ \\
\hline
\end{tabular}


a robust experimental design, especially as all of the papers identified were primary research articles. Secondly, it was identified whether the correct outcome variables had been measured for the type of study conducted. As the policy question focussed solely on farmland biodiversity, it was expected that suitable measures of abundance and richness would be reported alongside an effect size for the reader to interpret variation in results. Lastly, the papers were checked for evidence of selective reporting, including harking and p-hacking. It was expected that field-scale farmland research would include numerous variables relating to the hedgerow itself, as well as surrounding habitat features which may have an influence on the outcomes measured. If this was the case, then all variables measured should have been reported, whether positive or negative, significant at the $p<0.05$ level or not. A full report of the quality appraisal is provided in the extended data (Tresise, 2021; Table A.2).

By answering these questions in a yes/no/unclear format, it was possible to make a value judgement of the quality of the research paper, which could then be translated into an effect size of the research. The effect sizes used for the purpose of this review were small, medium and large (see Table 3 for definitions).

\section{Data extraction and synthesis}

Relevant data from the research papers collated was extracted into a qualitative summary information table of study characteristics (Table 4) and synthesis outcomes (Table 5), with further details found in the extended data, Table A.1 (Tresise, 2021). The latter was grouped broadly by intervention type: hedgerow management technique effects, comparisons of hedgerows to other boundary features and a comparison between mature vs newly planted hedgerows. A meta-analysis was not completed, owing to the fact that the outcome variables measured had been reported in different ways, including some as purely graphical. Where results were reported only in graphs and without any supporting material with the raw data, graphreader.com was used to extract estimates of the raw data (not including variation in error bars).

\section{Results}

The initial searches in Web of Science and Scopus identified 67 and 60 papers, respectively, and Google Scholar identified 296,000 matches. The inclusion and exclusion criteria applied in the first sift (by title and abstract) reduced the scientific database searches down to 17 papers each and 14 items were found in the first 100 hits of Google Scholar.
Overall, 29 of the 48 papers were duplicates and 13 papers were deemed unsuitable during the full text review ( $2^{\text {nd }}$ sift) or were not accessible, leaving six primary research papers. The bibliographies of these papers returned two further relevant articles, resulting in a final sample of eight papers (Figure 1). Study characteristics can be found in Table 4 .

\section{Review outcomes}

The main outcomes of this rapid review, given the available evidence, are three-fold. Firstly, there is a lack of peer-reviewed research looking into the direct effects of hedgerow age on farmland biodiversity. Secondly, hedgerow enhancement through coppicing, hedgelaying and shorter-term trimming regimes (biennial or triennial) appears to deliver a fairly consistent, positive effect on farmland taxa, lending a moderate amount of support to this component of the proposed net zero strategy. However, some of the research synthesised found no significant effects of hedgerow management on biodiversity. A comparison study between hedgerows and other boundary features demonstrated greater abundance and richness outcomes in green lanes (tracks usually bounded by hedgerows) than single hedges. This finding suggests that current hedgerow planting and management incentives could be adapted to include green lanes adjacent to hedges to further benefit both biodiversity and carbon storage, although this would need to take account of the higher management costs and effort required by farmers, and may only be possible on low productivity land. The most common taxa studied were invertebrates, including Lepidoptera, Coleoptera and Araneae, with no studies focussing on mammals and only one study including birds (although the strength of evidence was weak in this study). The following sections describe the key results, which have been broken down into the three main intervention themes found during the searches. A summary of findings can be found in Table 4 and a more detailed table of data extracted can be found in the extended data (Tresise, 2021; Table A.1).

Hedgerow management effects. Five of the eight papers looked into the effects of hedgerow management, including frequency, timing and technique, on biodiversity abundance and richness measures. Two studies focussed on hedge rejuvenation technique, including hedge-laying, re-shaping and coppicing (Amy et al., 2015; Sparks et al., 1996). Looking into short term hedge trimming effects on biodiversity, two papers analysed the impacts of cutting frequency (i.e. annual, biennial) and season of management (i.e. autumn or winter; Facey et al., 2014), as well as intensity of management

Table 3. Effect sizes for appraisal questions and definition.

\begin{tabular}{|l|l|}
\hline Effect size & Definition \\
\hline Small & None or one appraisal question met \\
\hline Medium & At least two appraisal questions met \\
\hline Large & All three appraisal questions met - i.e. causation, correct outcome measures and no selective reporting \\
\hline
\end{tabular}









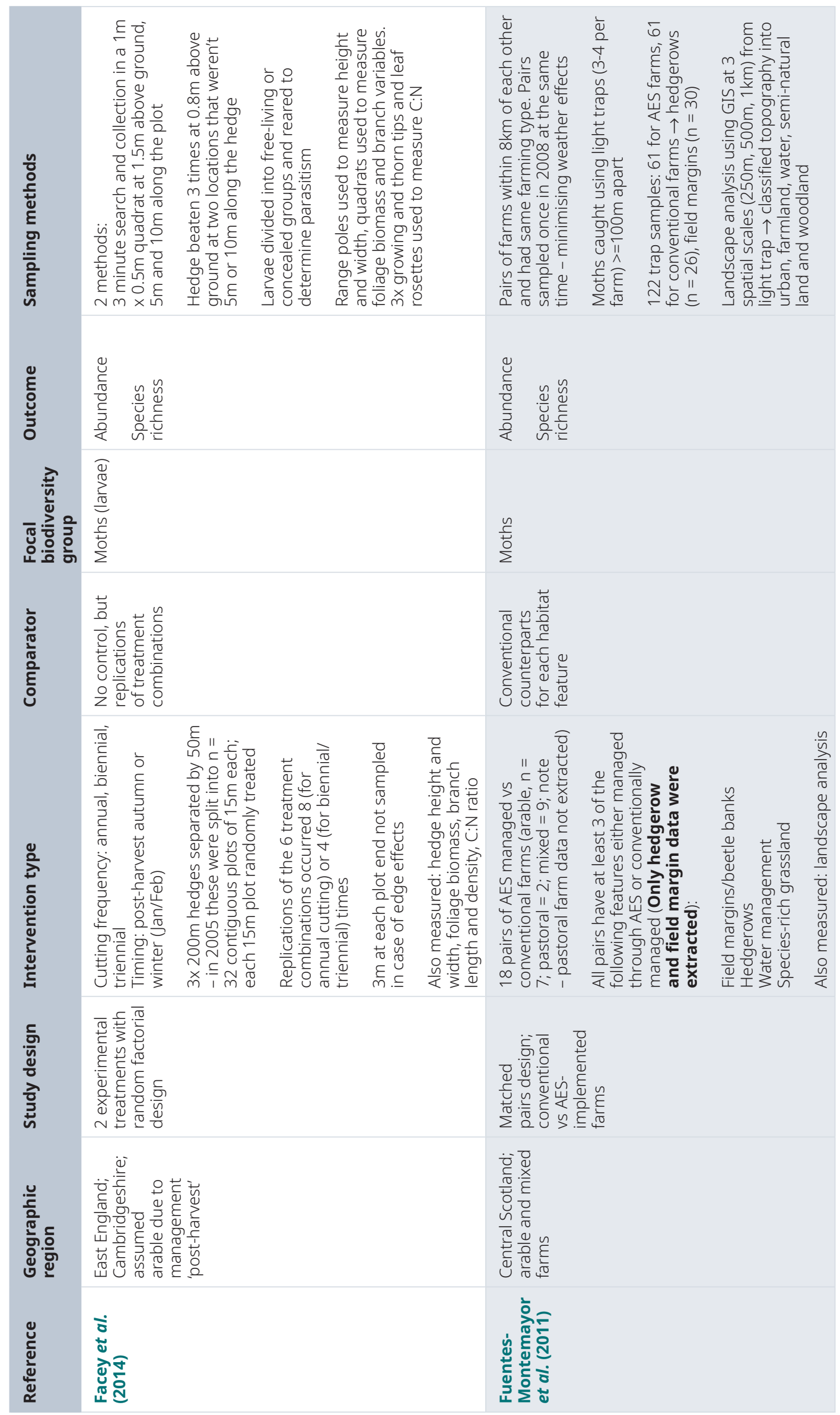




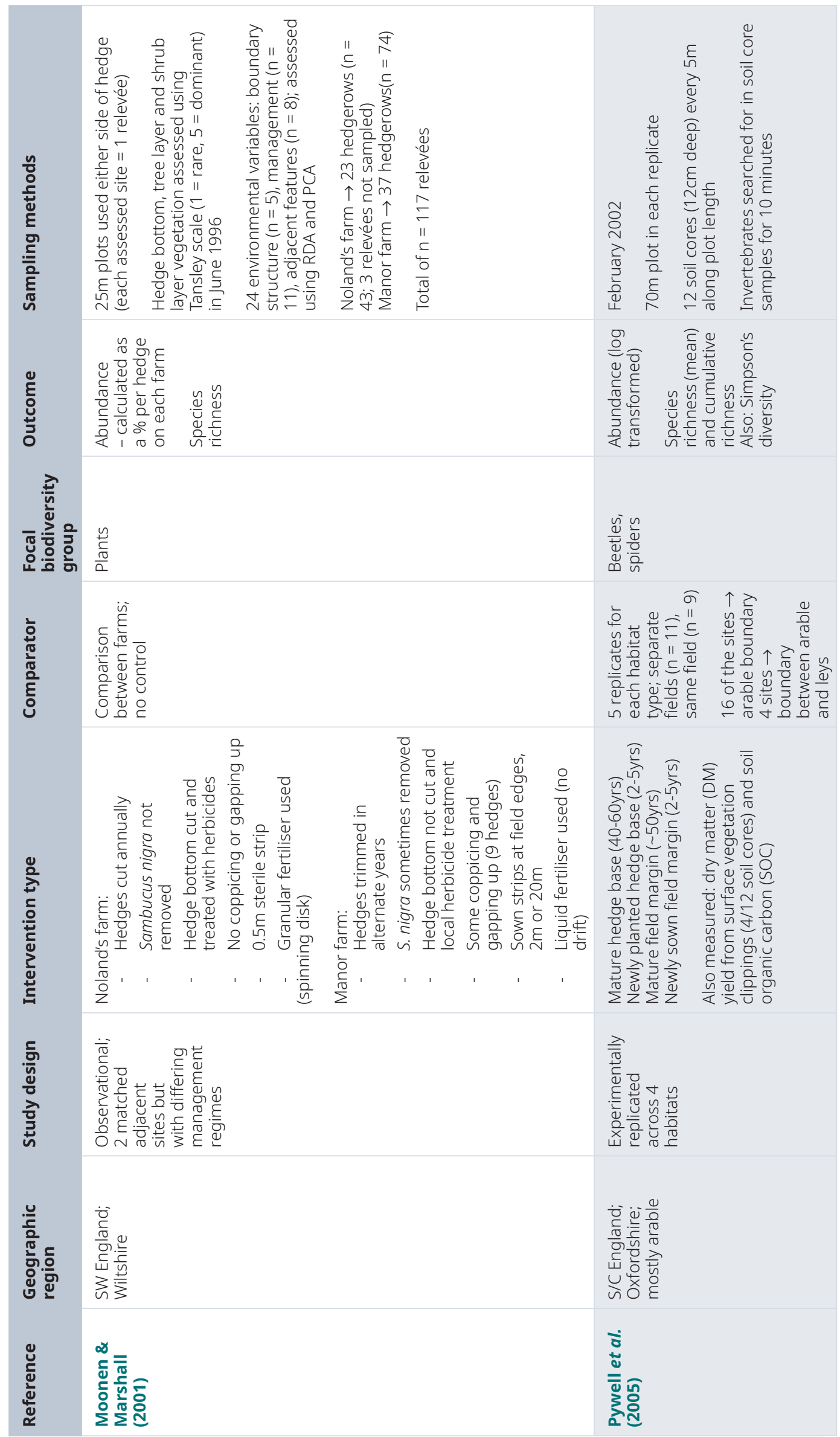




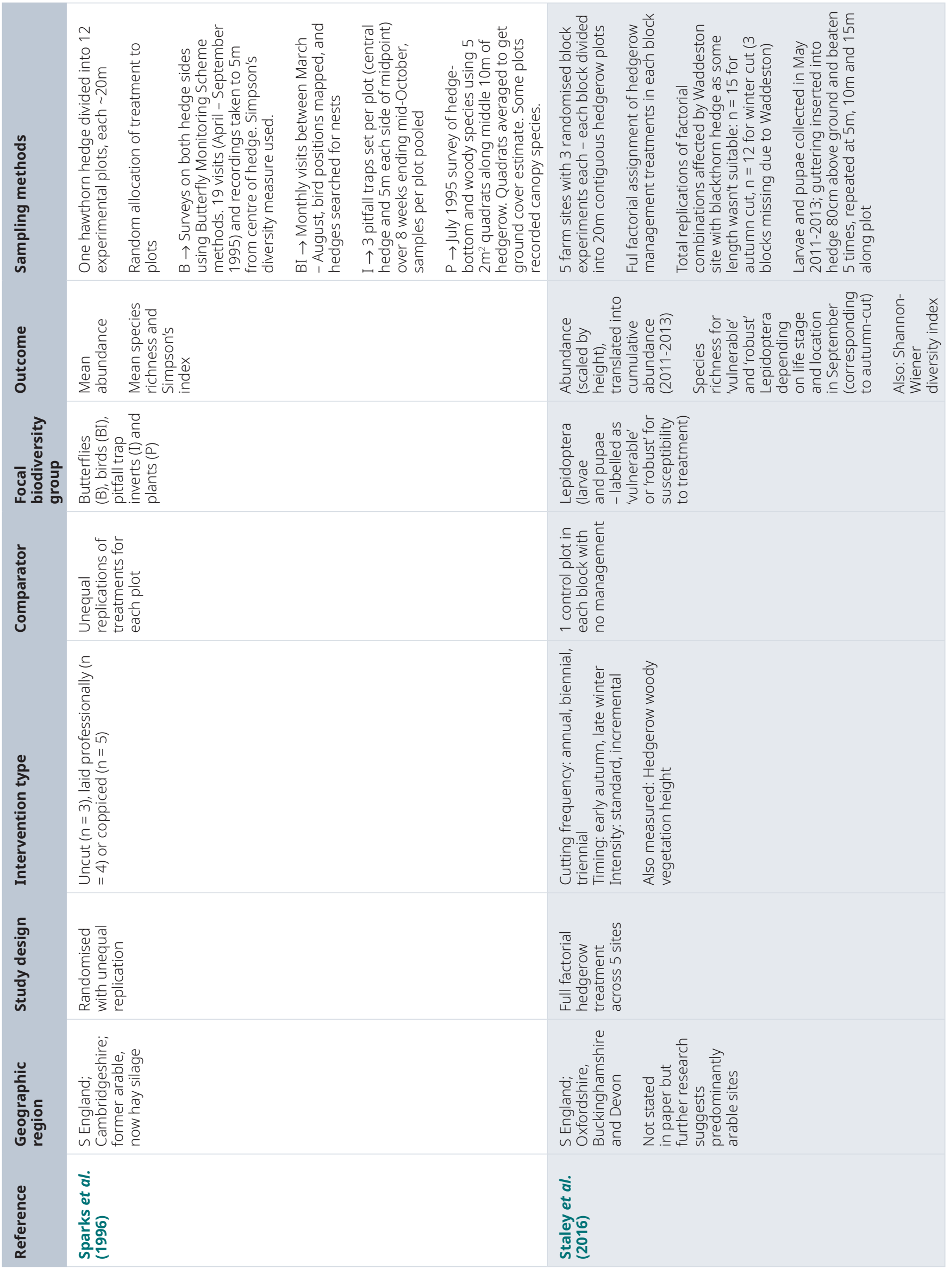


Table 5. Simplified effects from interventions on biodiversity outcome measures. Research paper effect sizes: ' $t^{\prime}=$ small effect, ${ }^{\prime}++^{\prime}=$ medium effect. Hedgerow effect on biodiversity: orange = negative effect, green = positive effect.

\begin{tabular}{|c|c|c|c|c|}
\hline Design & Reference & Intervention & Effect/Direction & Details \\
\hline \multirow[t]{5}{*}{$\begin{array}{l}\text { Hedgerow } \\
\text { management }\end{array}$} & Amy et al. (2015) & Hedgelaying & ++ & $\begin{array}{l}\text { Wildlife and Conservation hedgelaying are } \\
\text { just as beneficial to invertebrate abundance } \\
\text { as traditional Midland-style hedgelaying, } \\
\text { but more economical }\end{array}$ \\
\hline & Facey et al. (2014) & $\begin{array}{l}\text { Frequency \& Timing } \\
\text { of trimming }\end{array}$ & ++ & $\begin{array}{l}\text { Annual + winter cut or Biennial/triennial + } \\
\text { autumn cut best for moth abundance and } \\
\text { richness }\end{array}$ \\
\hline & $\begin{array}{l}\text { Moonen \& } \\
\text { Marshall (2001) }\end{array}$ & $\begin{array}{l}\text { Farm site } \\
\text { comparison: } \\
\text { frequency \& } \\
\text { technique }\end{array}$ & + & $\begin{array}{l}\text { Biennial trimming, as well as coppicing } \\
\text { and gapping-up rejuvenation techniques, } \\
\text { and adjacent sown strips better for plant } \\
\text { species }\end{array}$ \\
\hline & Sparks et al. (1996) & $\begin{array}{l}\text { Hedgelaying \& } \\
\text { coppicing }\end{array}$ & + & $\begin{array}{l}\text { Coppicing had greatest benefits overall for } \\
\text { taxa studied; weak study design }\end{array}$ \\
\hline & Staley et al. (2016) & $\begin{array}{l}\text { Frequency, timing \& } \\
\text { intensity }\end{array}$ & ++ & $\begin{array}{l}\text { Biennial/triennial cutting in winter was best } \\
\text { for Lepidoptera, some positive effects of } \\
\text { incremental management; inter-species } \\
\text { differences }\end{array}$ \\
\hline \multirow[t]{2}{*}{$\begin{array}{l}\text { Hedgerows and } \\
\text { other boundary } \\
\text { features }\end{array}$} & Dover et al. (2000) & $\begin{array}{l}\text { Hedgerows vs } \\
\text { green lanes, } \\
\text { grass banks and } \\
\text { woodland rides }\end{array}$ & + & $\begin{array}{l}\text { Green lanes were more beneficial to } \\
\text { butterflies than hedgerows, so adjacent } \\
\text { linear vegetative features could be } \\
\text { adaptation for net zero policy; weak study } \\
\text { design }\end{array}$ \\
\hline & $\begin{array}{l}\text { Fuentes- } \\
\text { Montemayor et al. } \\
\text { (2011) }\end{array}$ & $\begin{array}{l}\text { AES vs conventional } \\
\text { hedgerows and field } \\
\text { margins }\end{array}$ & ++ & $\begin{array}{l}\text { Hedgerows not as beneficial to moths as } \\
\text { field margins, particularly those under an } \\
\text { AES; Hedgerow AES should be re-visited } \\
\text { and contingency for field margin and } \\
\text { hedgerow expansion }\end{array}$ \\
\hline $\begin{array}{l}\text { Hedgerow age } \\
\text { effects }\end{array}$ & Pywell et al. (2005) & $\begin{array}{l}\text { Mature vs new } \\
\text { hedgerows and field } \\
\text { margins }\end{array}$ & ++ & $\begin{array}{l}\text { Hedgerows more beneficial to spiders and } \\
\text { beetles than field margins, although no } \\
\text { age effects found; time lag in community } \\
\text { richness/abundance increase expected and } \\
\text { pest presence }\end{array}$ \\
\hline
\end{tabular}

(incremental [raising the cutting bar $10 \mathrm{~cm}$ with each cutting event] or standard [cut at the same height each time]; Staley et al., 2016). Lastly, a two site comparison was used that analysed the effects of differing management regimes on two farms (Moonen \& Marshall, 2001). The overall findings from these papers are fairly consistent with current AES options for biodiversity improvement. Less frequent biennial and triennial trimming of hedges occurring in the winter, as opposed to autumn post-harvest, supported more biodiversity, and longer term hedgelaying through both traditional and more economical wildlife-conscious techniques achieved similar abundances of invertebrates. Therefore, a switch to more economic hedgelaying techniques, as opposed to traditional Midland-style laying, could be a consideration for net zero hedge expansion to keep costs lower whilst maintaining invertebrate communities.

\section{Management technique}

Hedgelaying techniques can have immediate effects on hedge structure, thus impacting the biodiversity that inhabit hedgerows, however rejuvenation through conservation hedgelaying $(\mathrm{CH})$ or wildlife hedging (WH) may support high numbers of invertebrates whilst being more cost-effective compared to Midland-style hedgelaying (MH; Amy et al., 2015). MH involves the removal of hedge branches and foliage, laying them on only one side of the hedge bound together with stakes; although there are other regional variants of this technique. $\mathrm{CH}$ is similar to $\mathrm{MH}$ except that branch stems are laid on both sides of the hedge, whereas WH is a novel technique where the entire hedge is pushed over. For images of these hedgelaying techniques, see Amy et al. (2015). These hedgelaying practices were carried out in October 2010, with subsequent invertebrate sampling and habitat structure analyses occurring throughout 2011 (January, May, July and September). A key finding was that, when scaled for the height of the hedgerow, the WH treatment often boasted higher abundances of herbivores and predators when compared with the two other hedgelaying methods, and the greatest abundance of detritivores of all the treatments. $\mathrm{CH}$ performed slightly poorer than $\mathrm{WH}$ in terms of invertebrate abundance, although 


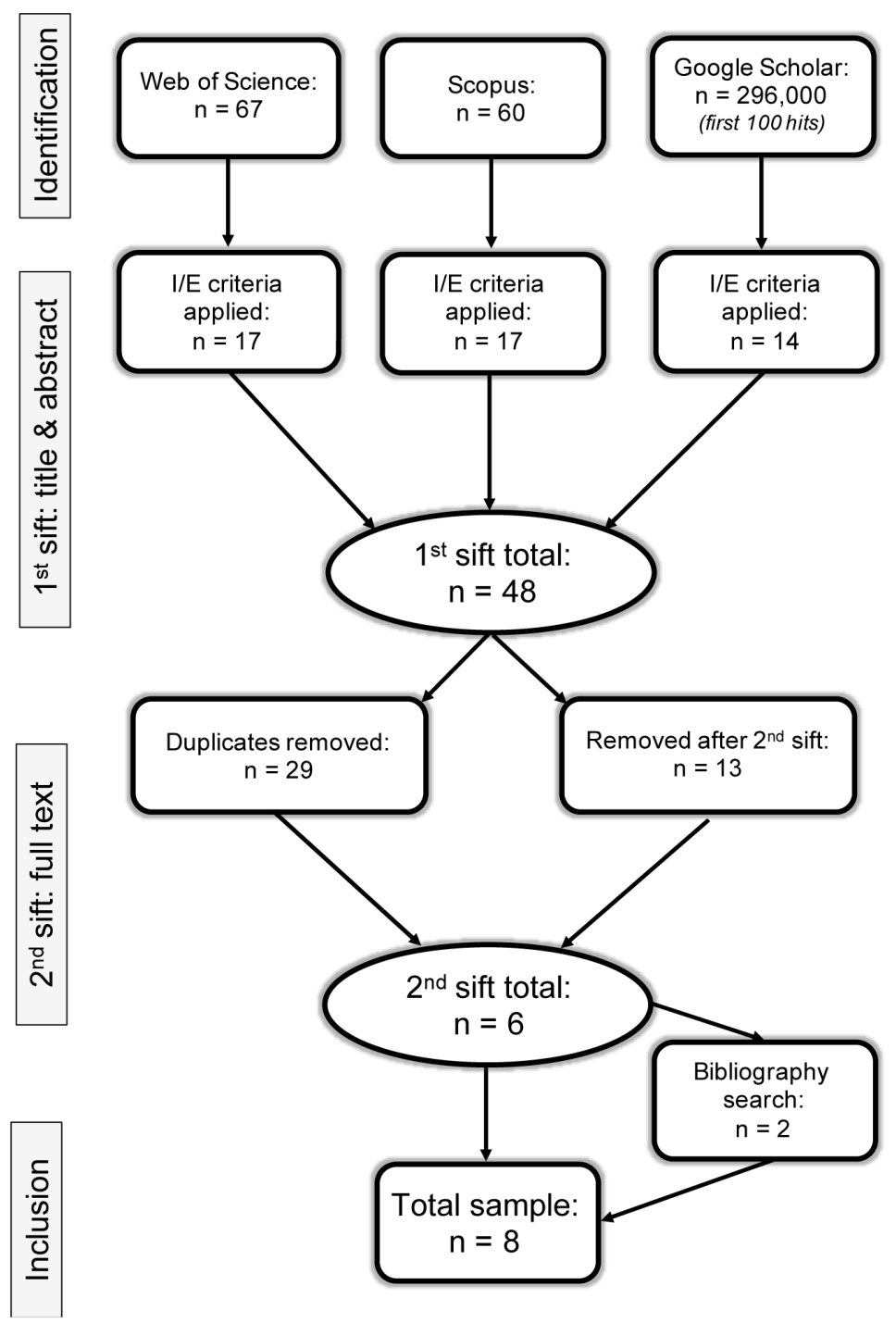

Figure 1. Flow chart depiction of the searching and sifting procedure used for the rapid review.

it had a higher foliage biomass $\left(\mathrm{g} / \mathrm{m}^{3}\right)$, gap area coefficient variable $\left(\mathrm{CV} ; \mathrm{cm}^{2}\right)$ and lateral branch volume $(\%)$ than $\mathrm{WH}$, indicating a more structurally diverse hedgerow. Furthermore, foliage biomass was significantly correlated with herbivore and predator abundance, with a $500 \mathrm{~g} / \mathrm{m}^{2}$ increase in biomass resulting in an increase of five herbivores and 15 predators on average. Although no measure of species richness was used, the authors did present brief findings of Shannon's Index for trophic group diversity, which found no significant effects of rejuvenation treatment and diversity.

Other research into hedgerow management technique compared uncut (i.e. no management where mean hedge height was $3.8 \mathrm{~m}$ ), laid (mean height $=2.4 \mathrm{~m}$ ) and coppiced hedges (to ground-level; mean height $=1.2 \mathrm{~m}$ ) on population measures of a variety of farmland taxa. A key finding was that managed hedges (particularly through coppicing) supported greater numbers and richness of butterflies, invertebrates and plants (Sparks et al., 1996). Butterfly records showed significantly more meadow brown (Maniola jurtina; 64\%) and hedge brown (or Gatekeeper; Pyronia tithomus; 20\%) Lepidoptera in laid hedges and coppiced hedges, respectively. Although richness of butterfly species did not differ significantly between treatments, Simpson's diversity index was significantly higher in coppiced hedgerows $(0.604 \pm 0.077)$. Too few birds were recorded to generate consistent significance levels, although woodpigeons (Columba palumbus) significantly preferred the taller, uncut hedges and, of the eleven total species recorded, five were breeding in the hedgerows (see Table 5). Invertebrates caught by the pitfall traps demonstrated no significant differences in abundance between treatments, except for the 16-spot ladybird (Tythaspis 16-punctata) and 
Scirtidae beetle family, which were significantly more abundant in coppiced hedges (93\% greater than uncut treatment) and uncut hedges $(3.3 \pm 1.7)$, respectively. Finally, plant abundance did not differ significantly between treatments, although a trend was noted where hedges under the laid or coppiced treatments had a higher percentage cover of bramble ( $R$. fruticosus) as hawthorn (Crataegus monogyna) percentage cover decreased (Table 5). No differences in the richness of invertebrate species were found.

\section{Trimming timing and frequency}

Two papers analysed the impacts of the timing and frequency of hedgerow trimming on Lepidopteran species that utilise these habitats on farmland, collecting specimens in their earlier life stages (larvae and pupae). Both papers found significant interactive effects of hedgerow management timing and frequency on total abundance of larvae, although with slightly differing outcomes. Research from Facey et al. (2014) demonstrated that neither timing nor frequency of hedgerow management had significant effects on moth larval abundance or richness measures, but that interactions between the two variables likely resulted in higher concealed moth abundance and greater parasitism proportion in the larvae they reared. For example, hedgerows that were cut annually in winter (9.9 individuals on average) or hedgerows cut less frequently in autumn (biennial: 9 individuals on average; triennial: 10.5 individuals on average) supported greater numbers of concealed larvae, but also resulted in higher proportions of parasitism in concealed moth larvae.

Conversely, research from Staley et al. (2016) demonstrated that the abundance of Lepidoptera larvae and pupae increased significantly under a winter hedgerow cutting cycle $(16 \%$ more larvae/pupae), particularly when managed every three years ( $4 \%$ increase), however the interaction between these management variables was marginally non-significant ( $\mathrm{p}=0.052)$. Richness of more vulnerable Lepidopteran species, those that occur on woody hedge vegetation as eggs, larvae or pupae at the start of autumn, increased by over half $(54 \%)$ under an autumn/triennial trimming management regime, however, richness of 'robust' species (those occurring as adults, larvae or pupae in soil detritus in September) was not significant for any treatment or interaction. The additional measure of trimming intensity (standard vs incremental) revealed marginally non-significant $(\mathrm{p}=0.054)$ trends in Lepidoptera richness, with an $18 \%$ increase in richness under incremental management. The findings illustrate that hedgerow management under a less frequent and less intense cutting regime can benefit Lepidopteran abundance and richness, although the timing of management may result in slightly different community compositions depending on life stage at time of cutting.

\section{Management comparison between farm sites}

A two-site case study demonstrated the impacts of varying hedgerow management practices, including different frequencies of hedge trimming, rejuvenation methods, sowing of strips adjacent to the hedge and agrochemical usage on hedge-bottom vegetation composition (Moonen \& Marshall, 2001). Key findings include that hedge-bottom plant species richness was significantly different $(\mathrm{p}<0.001)$ between the hedgerows at the two farms, with greater richness in the coppiced and gapped-up hedges found on Manor Farm (mean \pm SED: $23.2 \pm$ 1.36). The other hedgerows at Manor Farm achieved an average species richness of 17.4 plant taxa, and Noland's Farm had the lowest richness at 14.6 species. Further results indicate that rejuvenation of hedgerows using coppicing or gapping-up techniques also increased the landscape scale diversity of vegetation. Although the two farms were matched in terms of their homogenous soil types, farm size and field crop types, there was no control site and the management practices observed were farmer-led rather than from AES prescription or similar. Furthermore, no raw data was provided in the paper as abundance measures were presented in terms of percentage of hedgerows containing each species without error values. Therefore, the effect size of the study was deemed to be small, although the results that are presented suggest a positive direction for management of hedgerows similar to current UK AES policy where rotational coppicing and gapping-up are options for farmers.

Hedgerows and other boundary features. The farmed landscape is not limited to fields and hedgerows, as other boundary features are often present to further promote biodiversity, such as a field margins running parallel with a hedgerow, grass strips that can be sown with wildflowers, or areas of woodland, as well as stone walls, fences and ditches. The paper by Dover et al. (2000) considered the differences in butterfly populations between vegetated boundary features, including hedgerows, grass banks, woodland rides and green lanes (tracks or strips of corridor between two adjacent hedgerows). Significantly higher abundances and species richness of butterflies was found in the green lanes compared to other boundary features, including hedgerows, at two arable sites (Table 5). When butterflies were disaggregated to 'open' and 'closed' population species at the Warburton site, similar trends were found, with closed population species being significantly $(\mathrm{p}<0.05)$ more abundant inside green lanes (mean $=5.5 / 100 \mathrm{~m})$ compared to the outside of green lanes $(3.0 / 100 \mathrm{~m})$, hedgerows $(0.4 / 100 \mathrm{~m})$ and grass banks $(0 / 100 \mathrm{~m})$, and open population species were significantly $(\mathrm{p}<0.05)$ more abundant inside green lanes $(19.1 / 100 \mathrm{~m})$ compared to hedgerows $(9.3 / 100 \mathrm{~m})$ and grass banks $(6.3 / 100 \mathrm{~m})$.

Mean species richness for all species, as well as open and closed population species, at Warburton was significantly greater ( $p<0.05)$ inside and outside of green lanes compared to hedgerows and grass banks (see Table 5 for mean values). Species richness at the Warburton site was also significantly greater in the presence of other boundary habitat features including rough grassland $(\mathrm{p}<0.05)$ and ragwort (nectar source; $\mathrm{p}<0.05)$. When disaggregated to functional group, open population species richness declined significantly in grass banks $(\mathrm{p}<0.001)$ and hedgerows $(\mathrm{p}<0.01)$ and closed population species richness was significantly higher inside green lanes $(\mathrm{p}<0.01)$ and lower in grass banks $(\mathrm{p}<0.05)$. Rough grass adjacent to the boundary significantly increased total 
butterfly abundance, for both closed and open population species $(p<0.001$ for all). Other key factors significantly increasing abundance included thistle presence (nectar source) for all species $(\mathrm{p}<0.05)$ and thistle and ragwort for species in open populations $(\mathrm{p}<0.001$ for both).

Similar trends in butterfly abundance were found at the Manydown site, although slight differences occurred between years. Mean abundance was significantly higher $(\mathrm{p}<0.05)$ inside green lanes $(32.8 / 100 \mathrm{~m})$ for all species, as well as when divided into closed and open populations, in 1987 compared to hedgerows $(8.4 / 100 \mathrm{~m})$ and grass banks $(5.0 / 100 \mathrm{~m})$. However, by 1988 hedgerow and woodland ride butterfly abundance for all species had increased $(11.7 / 100 \mathrm{~m}$ and $22.0 / 100 \mathrm{~m}$, respectively) so that numbers were significantly higher inside green lanes and woodland $(\mathrm{p}<0.05)$ compared to grass banks $(7.5 / 100 \mathrm{~m})$, but not hedgerows. Closed population species followed the same trend, although were significantly $(\mathrm{p}<0.05)$ more abundant inside green lanes $(11.7 / 100 \mathrm{~m})$ and woodland rides $(14.1 / 100 \mathrm{~m})$ compared to both hedgerows $(4.3 / 100 \mathrm{~m})$ and grass banks $(0.8 / 100 \mathrm{~m})$. Open species showed no significant differences in abundance between habitat types in 1988 .

Critical appraisal of this study showed that despite evidence of causation, the sites cannot be treated as replicates due to the differences in treatment at the two sites and variables measured (e.g. nectar sources only recorded at Warburton). Moreover, not all variables measured were modelled to test for significance between treatments, (e.g. species richness at Manydown), therefore the overall effect size of the study is small (Dover et al., 2000).

Another paper examined the differences between matched pairs of AES managed and conventionally managed (i.e. not in any AES) farm boundary features in Scotland on adult moth populations (Fuentes-Montemayor et al., 2011). However, for the purpose of this rapid review only hedgerows and field margin evidence were synthesised in line with the research question. AES managed hedgerows included the following prescriptions: 1) hedge trimming on a triennial cycle with seasonal timing restrictions, 2) gapping-up of the hedge must occur, and 3) hedge-bottoms were to be left untouched. AES managed field margins include $1.5 \mathrm{~m}$ and $6 \mathrm{~m}$ sown grass margins around arable fields with agrochemical and grazing restrictions. They found no significant effects of AES hedgerow management compared to the conventional counterparts. Slightly higher numbers of macromoths were trapped next to AES hedgerows (219 compared to 203 on conventional farms), however micromoths captured at AES managed field margins were over three times as abundant compared to conventional field margins. Significantly interacting land management (AES or conventional) and habitat feature variables indicate that 3.7 times as many micromoths were recorded at AES managed field margins compared to conventional ones, although no significance was observed for hedgerows. For macromoth and declining moth species abundance, the effects of AES uptake on arable farms was significantly greater than mixed farms (macromoths: $\mathrm{p}<0.001$; declining species: $\mathrm{p}<0.01$ ). Comparable results were found for species richness, with AES managed features generally supporting more moth species than conventional farms. Micromoth richness was significantly greater $(3.8 x)$ at AES managed field margins compared to conventional counterparts $(\mathrm{p}<0.001)$. However, both macromoth and declining moth species richness were not significantly affected by AES participation $(\mathrm{p}>0.05)$.

A spatial landscape analysis revealed that semi-natural cover (e.g. rough grass and scrub) significantly and positively predicted micromoth and macromoth abundance, and macromoth and declining macromoth species richness at local scales (i.e. $250 \mathrm{~m}$ from the collection site) (Fuentes-Montemayor et al., 2011). These findings could suggest a contingency for improving AES prescriptions for hedgerows by ensuring scrub and rough grass habitat are maintained at the base of hedgerows, providing better shelter from predators and larval food resources. The overall conclusion of this paper was that AES management could improve moth populations, particularly on field margins. However, the effect size was deemed medium, as despite the robust experimental design and analysis, the sampling method of light trapping adult moths has been widely criticised (e.g. Facey et al., 2014).

Hedgerow age effects. There is a clear lack of peer-reviewed research examining the effect of hedgerow age on biodiversity in a farmland context and, arguably, this would be one of the most important factors to consider for both carbon sequestration and biodiversity improvement. The only paper identified during the search that related to hedgerow age studied the impacts of new versus mature hedgerows and field margins on spider and beetle abundance and species richness (Pywell et al., 2005). Hedgerows had a significantly greater abundance $(\mathrm{p}<0.05$; mean $\pm \mathrm{SE}=383.5 \pm 53.0)$ and cumulative species richness $(\mathrm{p}<0.05 ; 13.4 \pm 0.9)$ of Staphylinidae beetles compared to the field margin (abundance: $197.3 \pm 40.4$; cumulative richness: $10.6 \pm 0.6$ ). No significant differences in beetle or spider abundance or species richness was found between newer $(2-5$ years $)$ and older $(40-60$ years $)$ hedgerows, although individual species of carabid beetle (Bembidion lampros; p < 0.05), staphylinid beetle (Lathrobium elongatum; $\mathrm{p}<0.01$ ), the brassica pest Meligethes aeneus $(\mathrm{p}<$ $0.01)$ and Phyllotreta atra $(\mathrm{p}<0.05)$ were all significantly more abundant in mature hedge bases (see Table 5).

B. lampros is a cereal aphid predator providing ecosystem services in mature hedgerows in the form of natural predation on pests and should therefore be considered when expanding hedgerow area as a net zero strategy. It may take five years or more to develop a rich and diverse invertebrate community, including natural predators, in newly planted hedgerows, as well as to sequester atmospheric carbon for soil storage, thus biodiversity and climate mitigation effects will come with a time lag (Pywell et al., 2005). This research provided an in-depth analysis of hedgerow age effects on arable farmland, with all variables measured reported in a clear format and accounted for multiple population measures. However, 
the samples were collected from only a single-site in Oxfordshire (England) so transferability of the results elsewhere in the UK or further afield may be limited. Hence, the overall effect of the research was allocated as 'medium' and comes with contingencies to hedgerow expansion that involve expecting at least a 5-year time lag for invertebrate assemblages to develop in the new hedgerows and to be cautious of crop pest-predator cycles that may not develop until hedgerows are mature.

\section{Discussion}

The pressure is building to find effective strategies that reduce GHG emissions and sequester and store atmospheric carbon dioxide to mitigate further climate change, whilst minimising environmental degradation or biodiversity loss. There is no silver bullet for achieving net zero, especially not from agricultural systems, considering their vast complexity and diversity. Afforestation through woodland planting and agroforestry, as well as hedgerow planting and enhancement, are examples of nature-based solutions to the climate crisis, aiming to draw down and store atmospheric $\mathrm{CO}_{2}$ as organic carbon in biomass and soils (Paustian et al., 2016; Smith, 2012). As hedgerows constitute a variety of perennial woody species and are already a common feature on UK farmland, they fit this requirement well. The $\mathrm{CCC}$ have advised that hedgerow area in the UK should be extended by $40 \%$ to around 181,000 ha, roughly an extra $200,000 \mathrm{~km}$, by 2050 and the NFU expect hedgerows to sequester $0.5 \mathrm{MtCO}_{2} \mathrm{e}$ every year, although following a different timeline of net zero agriculture by 2040 and without providing the calculations for this figure. However, there is a clear lack of evidence examining the impacts of hedgerow planting, and thus age, on the taxa that utilise hedgerows, as shown in this rapid review.

\section{Hedgerow management effects}

Within the hedgerow management papers, there are mixed findings in terms of management timing (autumn or winter), although the evidence more strongly suggests a biennial or triennial trimming frequency and longer-term coppicing and hedgelaying is more beneficial for the taxa studied and is aligned already with current rural policy. Additionally, research has shown that incremental hedgerow cutting (creating a wider, taller hedge) may increase Lepidopteran species richness by almost $20 \%$ (although non-significant), compared to standard management that usually cuts hedges to the same height and width each time (Staley et al., 2016). The other paper to focus on the timing and frequency of trimming also examined parasitism rates amongst treatments, and found that parasitism of moth larvae increased significantly in the same treatment combinations that increase larval abundance (Facey et al., 2014). This single piece of evidence in this review provides an important contingency for net zero hedgerow policy, as more evidence is needed in a separate systematic review to focus on predator-prey and parasite-prey relationships in and around hedgerows. If hedgerow planting is expanded across the farmed landscape, this could interfere with stable predator-prey cycles and parasitism rates across multiple taxa. Further research is needed to examine the impacts of planting new hedgerows on these relationships for all biodiversity that utilise hedgerows for food and shelter (e.g. from predators).

Longer term rejuvenation techniques also played an important role for biodiversity outcome measures, with coppicing, gapping-up and hedgelaying being mostly positively associated with higher abundance and richness of taxa. Sparks et al. (1996) used multiple biodiversity groups to demonstrate the impacts of hedgelaying and coppicing compared to an uncut control and found mixed results between taxonomic groups. Butterflies were the only group to demonstrate a significant increase in mean abundance between the management treatments and uncut hedges, with the Meadow Brown being more commonly recorded in laid hedges and Gatekeeper butterflies in coppiced hedges. These findings were attributed to the fact that the managed treatments bore more ground flora and canopy plant species that provide nectar sources for butterflies and the densely laid hedgerows could have provided shelter from high wind speeds for the meadow brown (Sparks et al., 1996). Non-significant species richness results were observed for all groups; however, richness was generally greater in laid and coppiced hedges for butterflies, and coppiced hedges for plants. Overall, the implications of the findings in this paper suggest that hedgerow rejuvenation through coppicing and hedgelaying remain beneficial to farmland biodiversity. This lends support to hedgerow expansion as a component of net zero policy, under the assumption that less mature hedgerows will be rejuvenated at the correct time in their growth cycles, as well as current hedgerows that have been over- or under-managed being rejuvenated to promote growth, and therefore biodiversity and carbon sequestration in woody biomass. More recent research, looking specifically at hedgelaying effects on invertebrate communities, found similar benefits of hedgelaying when compared to using a circular saw to re-shape a hedgerow, although not for the unmanaged hedgerow, which when scaled for height had 2.2 times as many herbivorous and 1.9 times as many predatory invertebrates than conservation and Midland-style laying treatments (Amy et al., 2015). This is likely due to the immediate consequential effects of hedge management on the structure of the vegetation, which then impacts invertebrate community structure. However, with time the rejuvenation effects diminish, and findings show that conservation and wildlife hedging may be both beneficial for invertebrate populations, but also more cost-effective than traditional Midland-style hedgelaying procedures.

Other research into hedgerow management techniques revealed similar findings to the previous papers, as coppiced and gapped-up hedgerows supported significantly higher herbaceous plant species richness in hedge-bottoms compared to hedgerows that had not been rejuvenated (Moonen \& Marshall, 2001). Gapping-up is a process of planting new hedgerow vegetation in current hedge gaps to promote a more diverse structural hedgerow, thus these findings lend some support to net zero hedgerow policy in that this practice can promote the colonisation of a wide range of plant species, which can also be 
used as a food resource by other taxa and also become a carbon sink. However, further research is still needed to identify how hedgerow age impacts on biodiversity, with gapping-up treatments included, to build evidence of the multifunctionality of hedgerows. Another finding included the significant difference in plant species composition of the tree and shrub layers of hedgerows at Noland's Farm and Manor Farm. For example, significantly fewer hedgerows at Manor Farm had $P$. spinosa and $R$. fruticosus in the shrub layer, and $C$. monogyna and $S$. nigra in the tree layer compared to Noland's Farm. The lower abundance of $S$. nigra at Manor Farm can be explained by the fact that the manager occasionally removes this plant from hedge-bottoms as it is a rapid colonising species that can compete with $C$. monogyna post-cutting (Moonen \& Marshall, 2001). Lastly, the abundance of several known weed species (Aisantha sterilis, Galium aparine, Urtica dioica and Poa trivialis) was reduced in the presence of sown grass strips and hedge-bottom species richness was also significantly increased by sown strips $(p<0.05)$. This presents an interesting possible contingency for net zero hedgerow policy, as these results indicate that hedgerow plant species, which could benefit other taxa that utilise hedgerows, can thrive without competition from weed species when grass or grass-flower strips are sown adjacent to the hedge.

\section{Hedgerows and other boundary features}

Two papers with different methodologies that directly compared hedgerows to other vegetated boundary features both concluded that hedgerows were not overly important to Lepidopteran species compared to features such as field margins (especially under AES management) and green lanes. Both abundance and species richness of butterflies at the arable Warburton site were consistently significantly $(\mathrm{p}<0.05)$ greater in green lanes, compared with grass banks and hedgerows. Additionally, habitat features including presence of rough grassland and ragwort significantly improved overall species richness, and richness of closed population species $(\mathrm{p}<0.05)$. The other arable site used in the study included woodland rides, rather than an outside green lane variable, and presented opposing significant trends in open and closed species abundances. Using the 1987 data, the authors demonstrated that woodland rides had significantly more closed species butterflies than grass banks and hedgerows, although open species and overall species were significantly lower in abundance in woodland rides compared to inside green lanes $(\mathrm{p}<0.05)$. Green lanes provide more shelter, which may be appealing to butterflies, although wind speeds recorded during the study were variable between habitats. Finally, significantly more bramble was recorded inside of green lanes, which is an important source of nectar for butterflies. Green lanes appear to be a superior habitat for butterflies than single hedgerows, which could be a possible adaptation to future hedgerow expansion under net zero policies. However, there are costs associated with hedgerow management and farmers may not find the additional work appealing or cost-effective unless additional costs were reflected in AES payment levels.

Similar findings were observed for moth species, in which hedgerows, whether managed under AES prescription or not, were less important for abundance of species richness measures compared to field margins (mainly AES). Macromoth abundance and species richness was higher under AES hedgerow management compared to the conventional counterparts, although non-significant. On the other hand, AES field margins supported significantly more micromoths compared to conventional margins, which may be the result of greater vegetative diversity and cover in an AES prescriptions, which enables micromoths to avoid predators and find larval food sources (Fuentes-Montemayor et al., 2011). The landscape analysis of land cover at different scales showed consistent positive trends, with local (within $250 \mathrm{~m}$ ) semi-natural habitat cover significantly predicting micromoth and macromoth abundance, and macromoth and declining species richness. Contingencies for the net zero hedgerow initiative in this case include sowing and management of adjacent field margins under AES prescription and improving hedgerow AES prescriptions through the inclusion of more semi-natural scrub at hedge bases.

\section{Hedgerow age effects}

With only a single paper available that directly examines hedgerow age effects on biodiversity (beetles and spiders), there is a clear need for further research in this particular area, given the rate of hedgerow planting that is going to occur in the UK. The comprehensive analysis of mature and newly planted hedgerows in comparison with mature and newly sown field margins revealed no significant age effects, except for a higher Simpson's diversity of Staphylinid beetles in mature hedgerows. Overall, hedgerows supported significantly greater abundances, mean richness and cumulative richness when species of Coleoptera and Araneae were combined. Spider abundance was non-significant for both habitat type and age, although lower overall numbers of individuals were collected during sampling which could explain the lack of significance. Interaction between habitat type and age were found for several individual species, including the cereal aphid predator B. lampros, and the brassica pest M. aeneus, which were more abundant in mature hedge bases. As no significant age effects as a single factor were found, further research should be conducted to corroborate these findings and delve further into the age effects of hedgerows on the biodiversity that utilise them. This further research should also include other taxa, such as mammals and birds that are also likely to be impacted by recently planted hedgerows.

\section{Research implications}

Implications for policy

Although there is a general consensus amongst the research studies found that hedgerow planting and enhancement may have neutral (in comparison with other vegetated boundary habitats) or even positive effects on farmland biodiversity, the strength of the evidence is too weak to suggest many definitive policy implications. The most common taxa featured in the articles synthesised were invertebrates, typically moths, butterflies, beetles and spiders. There is evidence to suggest that invertebrate assemblages will not be affected by hedgerow planting, and thus age effects, but these may be positively affected by AES regulated hedgerow cutting, such as biennial 
or triennial trimming in winter and long-term restructuring, e.g. hedge laying. However, several of these studies used other vegetated boundary features, e.g. field margins, as comparators to hedgerows and found higher abundance and richness outcomes in these non-hedge habitats. An implication for policy could therefore be that if hedgerow expansion does occur as part of net zero policy, there must be other boundary habitat available (e.g. grass margins) and future management, i.e. trimming, of the newly planted hedgerows must follow AES regulations to maintain these habitats. It is possible that bird and mammal research has been excluded from initial sifts of this review due to the more stringent criteria applied as a rapid review. However, as invertebrates were the most common taxa studied amongst the literature found in this review further research and reviews will be needed using other taxa, particularly birds and mammals, before solid conclusions about the biodiversity implications of hedgerow expansion can be made. Given the well-known historic impacts of agriculture on farmland biodiversity (Butler et al., 2007; Kleijn et al., 2009) it is important that net zero policy options for agriculture should include potential effects on biodiversity using evidence synthesis.

\section{Implications for research}

From the literature gathered in this rapid review, it is evident that further scientific research is needed to fully comprehend the breadth of implications of hedgerows, specifically planting and enhancement, on the biodiversity common to arable farmland in the UK. Although the research base for hedgerow management, whether in line with current AES policy or more traditional practice, is greater than that of hedgerow planting studies, it is imperative that a wider variety of farmland taxa are also studied.

The majority of the studies found focussed on invertebrate communities in hedgerows, predominantly Lepidoptera, Coleoptera and Araneae. None of the research articles found presented a more in-depth study of bird and mammal assemblages that use hedgerows as foraging and nesting habitats, yet these taxa form the higher end of the ecosystem food chain. To gather a robust, evidence case for improving or maintaining biodiversity whilst expanding hedgerows as a net zero strategy, it is necessary to evaluate the impacts of hedgerow planting and enhancement for all taxa that utilise hedgerows. Therefore, further evidence synthesis of hedgerow planting and management impacts on other farmland taxa is needed in order to infer a confident policy recommendation for the expansion of hedgerows on farmland, particularly on grasslands as this was not covered in the scope of this review.

Furthermore, only one article was found to directly compare the effects of new and mature hedgerows on farmland biodiversity, an intervention that directly relates to the concept of using hedgerows as a carbon sequestration method, although no significant age effects were found. Therefore, further research is needed to analyse the effects of hedgerow planting on a variety of farmland taxa to further understand age effects on biodiversity that utilise these habitats.

\section{Data availability}

\section{Extended data}

OSF: Effects of hedgerow enhancement as a net zero strategy on farmland biodiversity: a rapid review. https://doi.org/10.17605/ OSF.IO/KPC3X (Tresise, 2021)

This project contains the following extended data:

- Supplementary_Information_v2.docx (Summary characteristics table and critical appraisal report)

- Rapid Evidence Synthesis Protocol.docx

Data are available under the terms of the Creative Commons Zero "No rights reserved" data waiver (CC0 1.0 Public domain dedication).

\section{Acknowledgements}

This rapid review was delivered from the Rapid Evidence Synthesis Training (REST) programme, organised and delivered through a collaboration between the University of Leeds, Newcastle University and the N8 AgriFood Programme. REST was also supported by Research England QR-SPF funds from the University of Leeds and University of York. Additional thanks go to Dr Gavin Stewart for conducting the REST training and residential workshop, as well as his input in conceptualising this review, and Dr Marcelo Galdos for his input on the final edits of this paper.

\section{References}

Amelung W, Bossio D, de Vries W, et al: Towards a global-scale soil climate mitigation strategy. Nat Commun. 2020; 11(1): 5427.

PubMed Abstract | Publisher Full Text | Free Full Tex

Amy SR, Heard MS, Hartley SE, et al.: Hedgerow rejuvenation management affects invertebrate communities through changes to habitat structure. Basic Appl Ecol. 2015; 16(5): 443-451.

Publisher Full Text

Axe MS, Grange ID, Conway JS: Carbon storage in hedge biomass - A case study of actively managed hedges in England. Agric Ecosyst Environ. 2017; 250: 81-88.

Publisher Full Text
Burel F: Hedgerows and Their Role in Agricultural Landscapes. CRC Crit Rev Plant Sci. 1996; 15(2): 169-190. Publisher Full Text

Butler SJ, Vickery JA, Norris K: Farmland biodiversity and the footprint of agriculture. Science. 2007; 315(5810): 381-384.

PubMed Abstract | Publisher Full Text

Carey P, Wallis S, Emmett B, et al.: Chapter $\mathbf{5}$ - Boundary and Linear Features Broad Habitat. NERC/Centre for Ecology \& Hydrology. Countryside Survey: UK Results from 2007. 2007; 50-60.

Reference Source

Donald PF, Green RE, Heath MF: Agricultural intensification and the collapse 
of Europe's farmland bird populations. Proc Biol Sci. 2001; 268(1462): 25-29. PubMed Abstract | Publisher Full Text | Free Full Text

Dover J, Sparks T, Clarke S, et al.: Linear features and butterflies: the importance of green lanes. Agric Ecosyst Environ. 2000; 80(3): 227-242. Publisher Full Text

Dover JW, Fry GLA: Experimental simulation of some visual and physical components of a hedge and the effects on butterfly behaviour in an agricultural landscape. Entomol Exp Appl. 2001; 100(2): 221-233. Publisher Full Text

Drexler S, Gensior A, Don A: Carbon sequestration in hedgerow biomass and soil in the temperate climate zone. Reg Environ Change. 2021; 21(74): 74 Publisher Full Text

Facey SL, Botham MS, Heard MS, et al.: Moth communities and agrienvironment schemes: Examining the effects of hedgerow cutting regime on diversity, abundance, and parasitism. A. Stewart \& N. Littlewood, eds.

Insect Conserv Divers. 2014; 7(6): 543-552.

Publisher Full Text

Fuentes-Montemayor E, Goulson D, Park KJ: The effectiveness of agrienvironment schemes for the conservation of farmland moths: assessing the importance of a landscape-scale management approach. J Appl Ecol. 2011: 48(3): 532-542.

Publisher Full Text

Graham L, Gaulton R, Gerard F, et al.: The influence of hedgerow structural condition on wildlife habitat provision in farmed landscapes. Biol Conserv. 2018; 220: 122-131.

Publisher Full Text

Green RE, Osborne PE, Sears EJ: The Distribution of Passerine Birds in Hedgerows During the Breeding Season in Relation to Characteristics of the Hedgerow and Adjacent Farmland. J Appl Ecol. 1994; 31(4): 677-692. Publisher Full Text

Higgins JPT, Thomas J, Chandler J, et al.: Cochrane handbook for systematic reviews of interventions Second edition. Hoboken, NJ: Wiley-Blackwell. 2020. Publisher Full Text

Kleijn D, Kohler F, Báldi A, et al.: On the relationship between farmland biodiversity and land-use intensity in Europe. Proc Biol Sci. 2009; 276(1658): 903-909.

PubMed Abstract | Publisher Full Text | Free Full Text

Moonen AC, Marshall EJP: The influence of sown margin strips, management and boundary structure on herbaceous field margin vegetation in two neighbouring farms in southern England. Agric Ecosyst Environ. 2001; 86(2): 187-202

Publisher Full Text

Paustian K, Lehmann J, Ogle S, et al.: Climate-smart soils. Nature. 2016; 532(7597): 49-57.

PubMed Abstract | Publisher Full Text
Petit S, Stuart RC, Gillespie MK, et al.: Field boundaries in Great Britain: stock and change between 1984, 1990 and 1998. J Environ Manage. 2003; 67(3): 229-238.

PubMed Abstract | Publisher Full Text

Pywell RF, James KL, Herbert I, et al.: Determinants of overwintering habitat quality for beetles and spiders on arable farmland. Biol Conserv. 2005; 123(1): 79-90. Publisher Full Text

Roe $\mathrm{S}$, Streck C, Obersteiner $\mathrm{M}$, et al.: Contribution of the land sector to a $\mathbf{1 . 5}$ ${ }^{\circ} \mathrm{C}$ world. Nat Clim Chang. 2019; 9(11): 817-828.

Publisher Full Text

Smith P: Soil carbon sequestration and biochar as negative emission technologies. Glob Chang Biol. 2016; 22(3): 1315-1324.

PubMed Abstract | Publisher Full Text

Smith P: Soils and climate change. Curr Opin Environ Sustain. 2012; 4(5): 539-544.

Publisher Full Text

Sparks TH, Bellamy PE, Eversham BC, et al.: The effects of three hedge management treatments on the wildlife of a Cambridgeshire hedgerow. Asp Appl Biol. 1996; 44: 277-284.

Reference Source

Staley JT, Botham MS, Chapman RE, et al.: Little and late: How reduced hedgerow cutting can benefit Lepidoptera. Agric Ecosyst Environ. 2016; 224: 22-28.

Publisher Full Text

Staley JT, Sparks TH, Croxton PJ, et al.: Long-term effects of hedgerow management policies on resource provision for wildlife. Biol Conserv. 2012 145(1): 24-29.

Publisher Full Text

Thomas J, Newman M, Oliver S: Rapid evidence assessments of research to inform social policy: taking stock and moving forward. Evid Policy. 2013; 9(1): 5-27.

Publisher Full Text

Tresise ME: Effects of hedgerow enhancement as a net zero strategy on farmland biodiversity: a rapid review. 2021

http://www.doi.org/10.17605/OSF.IO/KPC3X

Tresise ME, Biffi S, Field $\mathrm{R}$, et al: Drivers of songbird territory density in the boundaries of a lowland arable farm. Acta Oecologica. 2021: 111(103720): 103720.

Publisher Full Text

Tricco AC, Antony J, Zarin W, et al.: A scoping review of rapid review methods. BMC Med. 2015; 13(1): 224

PubMed Abstract | Publisher Full Text | Free Full Text 


\section{Open Peer Review}

\section{Current Peer Review Status:}

\section{Version 1}

Reviewer Report 25 February 2022

https://doi.org/10.21956/emeraldopenres.15397.r28003

(C) 2022 Smukler S. This is an open access peer review report distributed under the terms of the Creative Commons Attribution License, which permits unrestricted use, distribution, and reproduction in any medium, provided the original work is properly cited.

\section{Sean Smukler}

Faculty of Land and Food Systems, University of British Columbia, Vancouver, BC, Canada

In their manuscript the authors present a timely and important rapid review of the implications of hedgerow management on biodiversity in the context of the UK's net zero targets. The authors have used a standardized methodology to identify a set of peer-reviewed articles to extract information relevant to answering two clearly articulated research questions. Said simply: 1) What are the effects of hedgerows on biodiversity and 2) should we be concerned about any biodiversity trade-offs when using hedgerows to achieve a net-zero goal? The manuscript is well written, and provides some important lessons from the literature and helps to address the questions that they pose. While their conclusions are largely accurate, i.e. further research is needed to better address their questions, I do think that expanding their search to other temperate regions could provide important insight into the value and potential trade-offs for biodiversity of expanding the UK's hedgerow network.

\section{Abstract:}

The abstract does an effective job of concisely summarizing the manuscript.

\section{Methods:}

The methods are well described and appropriate.

\section{Results:}

The results were comprehensive and clearly presented. They provide a helpful synthesis of the eight papers that were reviewed.

\section{Discussion:}

The discussion provides some interesting and important commentary that contextualizes the results. I did however find the discussion to be somewhat redundant. The first paragraph of the discussion is fairly repetitive of the introduction and in other places the results are repeated more than perhaps necessary (e.g. I'm not sure that reporting P-values in the discussion is strategic). The authors also miss the opportunity in the discussion to bring in results from studies that could be informative from outside the UK. 
Is the topic of the review discussed comprehensively in the context of the current literature?

As mentioned above I would expand at the very least, the discussion to include studies outside of the UK.

Are all factual statements correct and adequately supported by citations?

I do not see any issues here.

Is the review written in accessible language?

The review is well written, but some readers might benefit from some additional definitions of terms.

Are the conclusions drawn appropriate in the context of the current research literature? Yes, these seem appropriate.

Is the argument information presented in such a way that it can be understood by a nonacademic audience?

The authors have done a nice job presenting the information to a non-academic audience.

Does the piece present solutions to actual real-world challenges?

I am not sure that any solutions were presented but certainly, the information here will help guide decision-makers and managers on the utility of hedgerows and their management in the context of two globally critical challenges: biodiversity loss and climate change. The information here also clearly identifies some key research gaps.

Is real-world evidence provided to support any conclusions made?

The manuscript and conclusions are firmly rooted in data that was gathered from real-world settings.

Could any solutions being offered be effectively implemented in practice?

Again, the results presented here offer some insights for better management of hedgerows to achieve multiple functions.

Is the work clearly and accurately presented and does it cite the current literature? Yes

Is the study design appropriate and is the work technically sound?

Yes

Are sufficient details of methods and analysis provided to allow replication by others? Yes

If applicable, is the statistical analysis and its interpretation appropriate? Yes

Are all the source data underlying the results available to ensure full reproducibility? 
Yes

Are the conclusions drawn adequately supported by the results?

Yes

Is the argument information presented in such a way that it can be understood by a nonacademic audience?

Yes

Does the piece present solutions to actual real world challenges?

Yes

Is real-world evidence provided to support any conclusions made?

Yes

Could any solutions being offered be effectively implemented in practice?

Yes

Competing Interests: No competing interests were disclosed.

Reviewer Expertise: Agroecology, agricultural beneficial management practices, ecosystem services, hedgerows

I confirm that I have read this submission and believe that I have an appropriate level of expertise to confirm that it is of an acceptable scientific standard.

Reviewer Report 14 October 2021

https://doi.org/10.21956/emeraldopenres.15397.r27744

(c) 2021 Montgomery I. This is an open access peer review report distributed under the terms of the Creative Commons Attribution License, which permits unrestricted use, distribution, and reproduction in any medium, provided the original work is properly cited.

\section{Ian Montgomery}

Institute of Global Food Security (IGFS), School of Biological Sciences, Queen's University Belfast, Belfast, United Kingdom

Although the article is billed as a 'Research Article', I have approached it as a 'Review' since it is titled a 'rapid review' and, as far as I can tell, there is no new data in the article apart from bibliometric data.

I welcome this paper as addressing an important topic that draws together the issues of agricultural GHG emissions and biodiversity loss associated with intensification of agriculture. Very little has been said at Government level with regards to hedges and their potential to contribute to zero carbon strategies and agricultural scientists tend to focus on production and technological 
means addressing carbon emissions. As a country that has a miserable level of tree cover, it is essential that we maximise the ecological value of our hedgerows not least with regard to net zero strategy and restoration of biodiversity. It is also a welcome initiative in linking these issues. Hedges are multipurpose and it is clear that good management generally benefits several ecosystem services but, occasionally, there may be conflicts with regards to management options. We should not lose sight of the bigger picture even where there may be data gaps. The overwhelming evidence from studies in the UK and throughout similar field based agriculture elsewhere, is that hedges provide a wide range of services and that more mature, greater volume hedges enhance carbon storage and biodiversity above and below soil level. They are a good thing.

\section{Abstract}

Describes the work concisely with respect to scope of review, broad methods, results and conclusions.

This is a very good, well referenced introduction to UK climate change policy, net zero strategy, hedgerows and their management in the UK. The authors have decided to focus on arable and the UK and hence, the review is relevant to southern and eastern Britain where arable systems prevail. This also happens to be where most research has been conducted, but it limits the value of the review. Pastoral agriculture in Britain and elsewhere contributes greatly to GHG emissions. The review gives the unintentional impression that emissions from some farms should be addressed whilst others can be ignored. It seems to me that all farms can contribute more to net zero strategy and to enhancement of biodiversity.

There are two ways to review a topic; here the authors focus on a narrow area and really dissect the literature in minute detail. This is a good way of evaluating the range and depth of the understanding provided by past research and identifying future directions. The alternative is a much more extensive review with less in-depth criticism with a view to describing activity across a research topic identifying common patterns and linkages. Thus, Tresise et al. (2021) complements the review we published in 2020 (Montgomery et al. 2020 ${ }^{1}$ ). We were limited in the number of references we could use. Most of the focal papers used by Tresise et al (2021) were referred to in the published manuscript or were included in the first draft of the AREES paper. Relevant work is also published by workers in other parts of western Europe and the coastal states of North American.

There are two further comments I would like to make. Although the authors state their questions clearly and their objectives are clear, I would like to see a clear definition of what a hedgerow is and what it is for and what biodiversity is and its contribution to farming and sustainable food supply. Although, hedgerows and biodiversity are good things, I think scepticism must be confronted. Hedgerows can provide a vital mitigation as weather becomes more extreme as well as valuable resources from browse to meeting net zero carbon strategies. Biodiversity is more than simply counting species - some farmland species are rare and have specific needs. Many provide pollination and pest protection services. Table 2 states 'Biodiversity richness'. This is not clear - do you mean 'species richness' or 'taxon richness'?

Methods

There is a very clear description of the process of screening commonly used databases. It is interesting to note the contrast in approach using linked terms. The authors do it one way and I 
would do it another using fewer linked terms but more terms e.g. with regards to pollinators or pest control in addition to 'biodiversity'. The authors might explore the literature comparing organis and conventional farms. Bristol University produced some well-worked comparisons involving bats and other taxa.

To avoid older readers (like me) having to guess, what exactly are 'harking and p-hacking'?

Results

The focal papers are well described and reviewed in the text and in Table 4. There are clearly gaps in the research on hedge management and in particular long term, experimental studies considering newly planted hedges and subsequent management. Most studies are descriptive and comparative. I feel that broadening the literature search to include non UK (e.g. bocage in France Burel et al $1989^{2}$ ), non arable, organic farms (Aude et al $2003^{3}$ ) and older literature on hedge age (e.g. Pollard's work in the $1970 \mathrm{~s}^{4}$ ), would enhance the overall conclusions of the paper under review.

\section{Discussion}

The Discussion partly repeats earlier results. The focus in the Discussion should be on policy and research implications. The overall conclusion is that improved hedgerow management can make a significant contribution to enhancing farmland biodiversity as well as contributing to a net zero strategy. However, the focus is mainly on extending hedgerow length. Increasing hedge volume (height and width), hedge maturity and reduced cutting, as well as reviewing constraints on hedgerow cutting and stricter enforcement of permitted cutting seasons, are also pertinent. Farmers should be required to manage hedgerows in a more sustainable way. A unidimensional approach to hedgerows might encourage some to remove what is there and to plant new hedges to qualify for subsidies. Many hedges are too narrow and low to contribute much to net zero strategy or address biodiversity loss. This is due largely to criteria established under CAP, that does not give a minimum hedge width although it does set a maximum that falls short of what might be desirable in a heterogeneous agricultural landscape. New regulations in the UK should review this. I would rather see no increase in overall hedgerow length but a minimum definition of a hedge as: $2 \mathrm{~m}$ at the base and midline height, cut no more than biennially and without gaps in excess of $5 \mathrm{~m}$. The objective should be to create a landscape where hedges present multiple opportunities for wildlife and the ecosystem services they provide. Thus, some hedges might be smaller and cut every $2-3$ years but others might be larger and cut at 10-15 years. The management of edges and verges complements that of hedges.

\section{Emerald OR Questions}

Is the topic of the review discussed comprehensively in the context of the current literature?

Within the limitations set by the authors. A less stringent application of these limitations bringing in some non-arable, non-UK and more extensive, descriptive and comparative studies would make the review more widely read and applicable.

Are all factual statements correct and adequately supported by citations?

Yes. The review is very well connected to the referenced work throughout.

Is the review written in accessible language?

Yes. There is some bibliometric jargon but nothing were the meaning is unclear. 
Are the conclusions drawn appropriate in the context of the current research literature? Within the limitations of the review the conclusions are well founded and justified.

Is the argument information presented in such a way that it can be understood by a non-academic audience?

This is a topic discussed widely outside academic ecology. There is nothing really I the review that is beyond a wide, non-academic readership.

Does the piece present solutions to actual real world challenges?

Solutions are a big ask. The review helps to make the point that improved hedgerow management can make a significant contribution to enhancing farmland biodiversity as well as contributing to a net zero strategy.

Is real-world evidence provided to support any conclusions made?

There is some work on real farms but I think there might be more 'real-world' evidence in the literature comparing organic and conventional farms.

Could any solutions being offered be effectively implemented in practice?

Yes. But it is worth considering actions beyond planting new hedges. Improving current hedges with respect to net zero strategy would be cost effective and have an immediate effect. The benefits for wildlife and many other ecosystem services provided by hedges e.g. mitigation of the effects of extreme weather, would also be considerable.

\section{References}

1. Montgomery I, Caruso T, Reid N: Hedgerows as Ecosystems: Service Delivery, Management, and Restoration. Annual Review of Ecology, Evolution, and Systematics. 2020; 51 (1): 81-102 Publisher Full Text

2. Burel F: Landscape structure effects on carabid beetles spatial patterns in western France. Landscape Ecology. 1989; 2 (4): 215-226 Publisher Full Text

3. Aude E, Tybirk K, Bruus Pedersen M: Vegetation diversity of conventional and organic hedgerows in Denmark. Agriculture, Ecosystems \& Environment. 2003; 99 (1-3): 135-147 Publisher

Full Text

4. Pollard E, Hooper MD, Moor NW: Hedges. Wyseby House Books.

Is the work clearly and accurately presented and does it cite the current literature? No

Is the study design appropriate and is the work technically sound? Yes

Are sufficient details of methods and analysis provided to allow replication by others? Yes

If applicable, is the statistical analysis and its interpretation appropriate? Not applicable

Are all the source data underlying the results available to ensure full reproducibility? 
Yes

Are the conclusions drawn adequately supported by the results?

Yes

Is the argument information presented in such a way that it can be understood by a nonacademic audience?

Yes

Does the piece present solutions to actual real world challenges?

Yes

Is real-world evidence provided to support any conclusions made?

Yes

Could any solutions being offered be effectively implemented in practice?

Yes

Competing Interests: No competing interests were disclosed.

Reviewer Expertise: Ecology, climate change, invasive species, agriculture impacts

I confirm that I have read this submission and believe that I have an appropriate level of expertise to confirm that it is of an acceptable scientific standard.

Author Response 30 Nov 2021

Megan Tresise, University of Leeds, Leeds, United Kingdom

Dear Professor Montgomery,

Apologies for the delay in responding to your comments, and I extend my thanks to you for your in-depth feedback of the review. I have taken onboard your suggestions and plan to submit a new version of the article in the New Year once I am back from my PhD secondment.

The scope for the review was narrow due to it being the product of a 1-day workshop and 2day residential with N8 AgriFood to learn the basics of rapid evidence synthesis. Otherwise, I agree completely that a broader review of both arable and pastoral systems, as well as hedgerow systems beyond the UK, would have been more favourable and relevant.

Thank you again for your suggestions and your time to review the paper.

Best wishes, Megan Tresise

Competing Interests: No competing interests were disclosed. 